\title{
Comparing combined gas tubrine/steam turbine and marine low speed piston engine/steam turbine systems in naval applications
}

\author{
Marek Dzida, Assoc. Prof. \\ Wojciech Olszewski, M. Sc. \\ Gdansk University of Technology
}

\section{ABSTRACT}

\begin{abstract}
The article compares combined systems in naval applications. The object of the analysis is the combined gas turbine/steam turbine system which is compared to the combined marine low-speed Diesel engine/steam turbine system. The comparison refers to the additional power and efficiency increase resulting from the use of the heat in the exhaust gas leaving the piston engine or the gas turbine. In the analysis a number of types of gas turbines with different exhaust gas temperatures and two large-power low-speed piston engines have been taken into account. The comparison bases on the assumption about comparable power ranges of the main engine.
\end{abstract}

Key words: marine power plants, combined systems, piston internal combustion engine, gas turbine, steam turbine

\section{INTRODUCTION}

In recent years combined systems consisting of a gas turbine and a steam turbine have started to be used as marine propulsion systems. In inland applications the efficiency of these systems can exceed $60 \%$. In naval applications such a system was used in Millenium, a passenger liner. But it is, so far, a unique case of propulsion system related with the highest efficiency. However, this system requires a more expensive fuel, which is the marine Diesel oil.

Another possible combined system can consist of a piston engine which cooperates with the steam turbine utilising the heat in the exhaust gas leaving the piston engine. The leading engine in this is system is always the piston internal combustion engine. The objects used as the main engines will be large low-speed piston engines which burn heavy fuel. At present, the efficiency of these engines reaches $45-50 \%$. In case of such large main engine power ranges, the exhaust gas leaving the piston engine contains huge amount of heat which can be the object of further utilisation.

Another possible solution of a combined system which can be applied in shipbuilding consists of a gas turbine, and a steam turbine which utilises the heat leaving the gas turbine. This heat can be used for production of steam which, in turn, can be used in the steam turbine cycle.

\section{CONCEPT OF A COMBINED SYSTEM}

Combined propulsion systems in naval applications are first of all used in fast special ships and in the Navy as the systems being the combination of a Diesel engine and a gas turbine (CODAG, CODOG) or gas turbines (COGOG, COGAG). The propulsion applied in the passenger liner Millenium makes use of a COGES system which increases the efficiency and operating abilities of the ship by combining the operation of a gas turbine with a steam turbine which drives the electric generator, while the propeller screws are driven by electric motors. In this system the steam turbine cycle is fed with the steam produced in the waste heat boiler supplied with the exhaust gas from the gas turbines.

Fig. 1 shows sample efficiency curves of the combined gas turbine/steam turbine systems as functions of power plant load, as compared to the gas turbine working in a simple open cycle and the marine low-speed Diesel engine. The analysis of the efficiency changes reveals that the combined system composed of a gas turbine and a steam turbine has the highest efficiency, which can reach up to $60 \%$ for maximal loads. Gas turbines working in a simple open cycle have the lowest efficiency, of an order of $33 \div 35 \%$ on average, and about $40 \%$ as the maximum [7]. Low-speed Diesel engines reach efficiency of an order of $47 \div 50 \%[5,6]$. At the same time their efficiency characteristics as functions of load are flat, which is of highest importance in marine propulsion systems working in heavily changing load conditions. For instance, the relative efficiency drop $\Delta \eta / \eta_{\mathrm{GT}}$ is equal to $15 \div 20 \%$ when the load changes from $100 \%$ down to $50 \%$ in the combined gas turbine/steam turbine systems and gas turbines working in a simple cycle, while for a low-speed Diesel engine this efficiency drop is equal to $1 \div 2 \%$. This property of the Diesel engine and utilisation of additional heat contained in its exhaust gas makes the application of this 
system very useful for marine propulsion systems working in extremely changing load conditions.

The temperatures of the exhaust gas from the gas turbines are equal to $450 \div 600^{\circ} \mathrm{C}$ on average, while for the low-speed Diesel engine these temperatures are of an order of $220 \div 300^{\circ} \mathrm{C}$ $[5,6]$, Fig. 2. But in the gas turbines this temperature remarkably decreases with decreasing load, while in the Diesel engine its changes are not high, nor monotonic: initially the temperature decreases and then starts increasing with the decreasing load.

This property of the Diesel engine in partial loads makes it possible to keep the temperature of the live steam at a constant level within a wide range of steam turbine cycle loads.

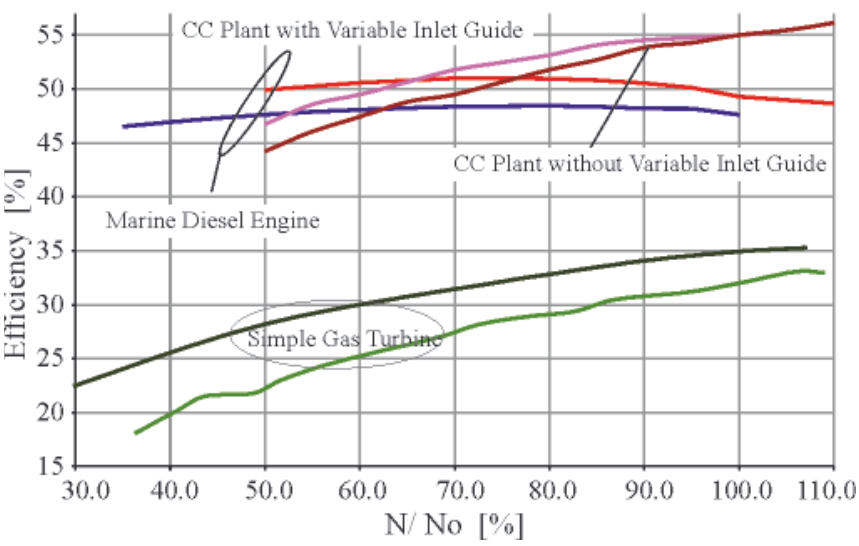

Fig. 1. Part-load efficiency of a combined-cycle plant (GT\&ST), simple gas turbine and marine Diesel engine

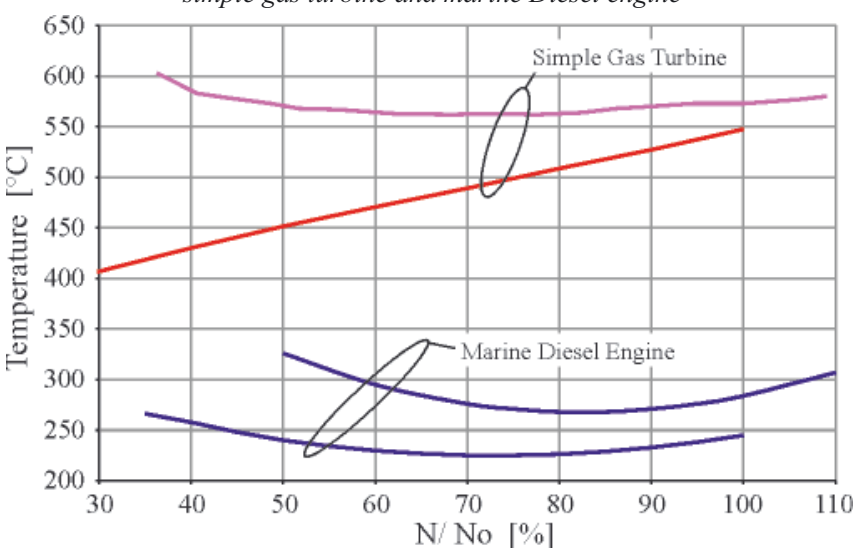

Fig. 2. Temperatures of the exhaust gas from the marine Diesel engine and the simple gas turbine as functions of power plant load

\section{Power evaluation of the combined propulsion system}

The power of the combined propulsion system is calculated by adding up particular power outputs of the system components, i.e. the main engine and the steam turbine:

$$
\mathrm{N}_{\text {combi }}=\mathrm{N}_{\mathrm{C}}+\mathrm{N}_{\mathrm{ST}}
$$

while the efficiency of the combined system is:

$$
\eta_{\text {combi }}=\frac{N_{\text {combi }}}{m_{\mathrm{f}} \cdot \mathrm{Wu}}=\eta_{\mathrm{D}} \cdot\left(1+\frac{\mathrm{N}_{\mathrm{ST}}}{\mathrm{N}_{\mathrm{C}}}\right)
$$

where:

$\eta_{\mathrm{C}}, \mathrm{m}_{\mathrm{f}}-$ are the efficiency and mass flow rate of the main engine.

It results from the relation (2) that each additional power in the propulsion system increases the efficiency of the system and, consequently, decreases the fuel consumption. The higher the additional power obtained from utilisation of the heat contained in the main engine exhaust gas, the lower the fuel consumption. In these circumstances we should tend to reach maximal power also from the steam turbine, in which the power output largely depends on proper selection of live steam parameters and condenser parameters.

\section{Steam turbine cycle}

The combined cycle makes use of the waste heat in the exhaust gas from the Diesel engine or the gas turbine. Adding a steam cycle to the combined Diesel engine or gas turbine cycle makes it possible to increase the power of the combined system, i.e. increase the system efficiency according to formula (2).

In case of small powers and low live steam temperatures in combined systems, single pressure systems are used [1, 2, 3], Fig. 3. Such a system consists of a single pressure waste heat boiler), a condensing steam turbine, a water cooled condenser, and a single stage feed water preheater in the deaerator.

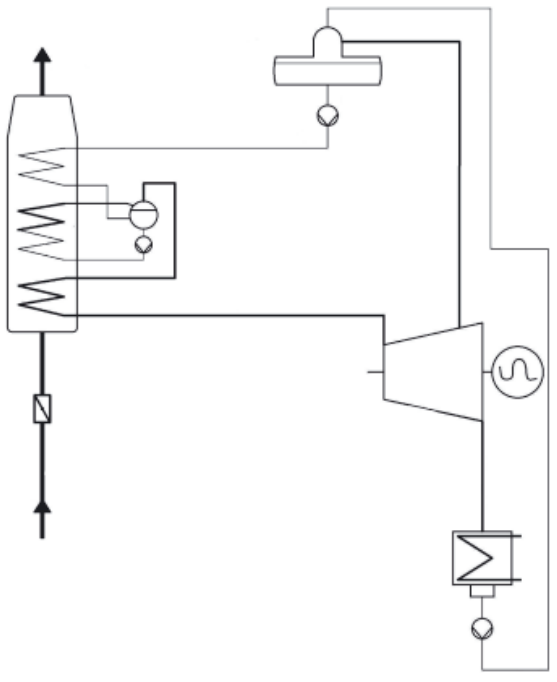

Fig. 3. Flow diagram of a single pressure system

The application of the single pressure system does not secure optimal utilisation of the energy in the exhaust gas when its temperature is high. The system which is most frequently used in these cases includes an additional low pressure evaporator $[2,3]$, Fig. 4, which not only increases the utilisation of the waste heat in the exhaust gas, but also provides opportunities for better thermodynamic use of the low-pressure steam.

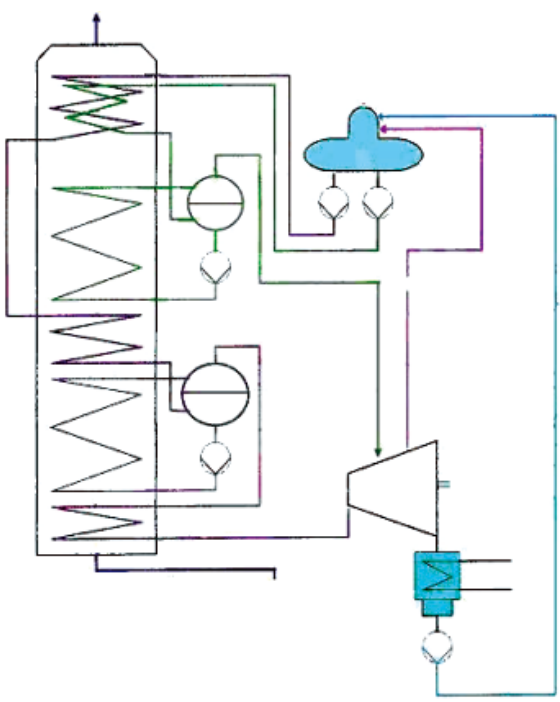

Fig. 4. Flow diagram of a two-pressure system 


\section{Limits of steam cycle parameters}

Limits of steam cycle parameters result from strength, technical, and durability conditions for particular system elements, but also from constructional and economic restrictions.

The temperature difference between the exhaust gas and the live steam was assumed equal to $\Delta \mathrm{t}=10^{\circ} \mathrm{C}$ in utilisation boilers used in shipbuilding, following the literature [3, 4]. The "pitch point" value recommended by MAN B\&W [4] for marine boilers was assumed equal to $\delta \mathrm{t}=10^{\circ} \mathrm{C}$. The limit of the steam dryness factor $\mathrm{x}$ behind the steam turbine was assumed equal to $\mathrm{x}_{\text {limit }}=0.86-0.88$. For marine condensers cooled with salt water, the company MAN B\&W [4] recommends assuming the condenser pressure equal to $\mathrm{p}_{\mathrm{K}}=0.065 \mathrm{bar}$. The temperature of the water which feeds the boiler is of high importance for the lifetime of the feed water heater in the boiler. MAN B\&W [4] recommends assuming that the feed water temperature is not lower than $120^{\circ} \mathrm{C}$, when the content of sulphur exceeds $2 \%$. The caloric value of the fuel was assumed constant and equal to $\mathrm{Wu}=42700 \mathrm{~kJ} / \mathrm{kg}$ in the calculations.

\section{Steam cycle optimisation}

The combined systems, in this case the steam cycles, should make maximal use of the heat contained in the exhaust gas from the main engine. Therefore the optimisation is reduced to calculating steam cycle parameters for which the steam turbine reaches the maximal power output. The area within which optimal steam cycle parameters are searched for is to be narrowed to the area in which all above listed limits and restrictions imposed on the steam cycle are fulfilled.
In case of combined systems with gas turbines, a twopressure steam turbine cycle is used. The calculations for the combined system with Diesel engines were performed for both the single- and the two- pressure variant. The steam turbine cycles in the combined systems were calculated based on the same schemes, and the same above listed assumptions and parameters.

\section{COMBINED GAS TURBINE/STEAM TURBINE SYSTEMS}

In the calculations of the combined systems with gas turbines a number of types of gas turbines produced by Alstom and GE were taken into account. The analysed turbines represented different power outputs and different exhaust gas temperatures. The total power output of the gas turbines in the combined system was kept close to each other in all variants. The gas turbine parameters which were assumed in the calculations are collected in Table 1.

Tab. 1. Parameters of gas turbines used in the combined gas turbine/steam turbine cycle [7]

\begin{tabular}{|c|c|c|c|c|c|}
\hline \multirow{2}{*}{$\begin{array}{c}\text { Type } \\
\text { of turbine }\end{array}$} & $\mathbf{N}_{\mathrm{GT}}$ & $\mathbf{m}_{\mathrm{GT}}$ & $t_{4}$ & $\eta_{\mathrm{GT}}$ & be $_{\mathrm{GT}}$ \\
\hline & kW & $\mathrm{kg} / \mathrm{s}$ & ${ }^{\circ} \mathrm{C}$ & - & $\mathrm{g} / \mathrm{kWh}$ \\
\hline CYCLON & 12900 & 39.7 & 570 & 0.340 & 248.0 \\
\hline GTX100 & 43000 & 122.0 & 546 & 0.370 & 227.9 \\
\hline GT10B & 24400 & 80.4 & 538 & 0.347 & 243.0 \\
\hline LM2500 & 22400 & 68.0 & 528 & 0.365 & 230.9 \\
\hline GT35 & 17000 & 92.3 & 378 & 0.320 & 263.5 \\
\hline
\end{tabular}

Tab. 2. Combined gas turbine/steam turbine cycle with two-pressure boiler

\begin{tabular}{|c|c|c|c|c|c|c|}
\hline Type & & CYCLON & GTX100 & GT10B & LM2500 & GT35 \\
\hline Number of engines & & 4 & 1 & 2 & 1 & 3 \\
\hline $\mathbf{N}_{\mathrm{GT}}$ & $\mathbf{k W}$ & 51600 & 43000 & 48800 & 44800 & 51000 \\
\hline $\mathbf{m}_{\mathrm{TG}}$ & $\mathrm{kg} / \mathrm{s}$ & 158.80 & 122.00 & 160.80 & 136.00 & 276.90 \\
\hline $\mathbf{m}_{\mathrm{f}}$ & $\mathrm{kg} / \mathrm{s}$ & 3.5542 & 2.7217 & 3.2935 & 2.8729 & 3.7324 \\
\hline $\mathbf{t}_{4}$ & ${ }^{\circ} \mathbf{C}$ & 570 & 546 & 538 & 528 & 378 \\
\hline $\mathbf{t}_{\mathrm{o}}$ & ${ }^{\circ} \mathrm{C}$ & 560 & 536 & 528 & 518 & 368 \\
\hline $\mathbf{p}_{0}$ & bar & 160 & 134 & 128 & 114 & 30 \\
\hline$p_{I}$ & bar & 4 & 4 & 3 & 3 & 2 \\
\hline $\mathbf{t}_{\mathrm{FW}}$ & ${ }^{\circ} \mathrm{C}$ & 120 & 120 & 120 & 120 & 120 \\
\hline $\mathbf{P u}$ & bar & 2.09 & 2.09 & 2.09 & 2.09 & 2.09 \\
\hline Mo & $\mathrm{kg} / \mathrm{s}$ & 20.88 & 14.58 & 18.57 & 15.23 & 18.28 \\
\hline $\mathbf{m}_{\mathrm{d}}$ & $\mathrm{kg} / \mathrm{s}$ & 3.88 & 2.87 & 3.75 & 3.1 & 4.14 \\
\hline $\mathrm{m}_{\mathrm{IT}}$ & $\mathrm{kg} / \mathrm{s}$ & 5.78 & 5.1 & 7.270 & 6.2 & 10.74 \\
\hline $\mathbf{N}_{\mathrm{ST}}$ & $\mathbf{k W}$ & 25304 & 17523 & 22232 & 18047 & 17713 \\
\hline $\mathbf{N}_{\mathrm{ST}} / \mathbf{N}_{\mathrm{TG}}$ & - & 0.4904 & 0.4075 & 0.4556 & 0.4028 & 0.3473 \\
\hline$\eta_{\text {combi }}$ & - & 0.5067 & 0.5208 & 0.5051 & 0.5123 & 0.4311 \\
\hline be $_{\text {combi }}$ & g/kWh & 166.4 & 161.9 & 166.9 & 164.6 & 195.6 \\
\hline $\mathrm{m}_{\mathrm{o}} / \mathbf{N}_{\mathrm{GT}}$ & kg/kWh & 1.4567 & 1.2207 & 1.3699 & 1.2238 & 1.2904 \\
\hline $\mathbf{m}_{\mathrm{d}} / \mathbf{m}_{\mathbf{0}}$ & $\%$ & 18.58 & 19.68 & 20.19 & 20.35 & 22.65 \\
\hline $\mathrm{m}_{\mathrm{IT}} / \mathbf{m}_{\mathbf{0}}$ & $\%$ & 27.68 & 35.12 & 39.15 & 40.71 & 58.75 \\
\hline $\mathbf{m}_{\mathrm{GT}} / \mathbf{N}_{\mathrm{GT}}$ & $\mathrm{kg} / \mathrm{kWh}$ & 11.08 & 10.21 & 11.86 & 10.93 & 19.55 \\
\hline
\end{tabular}


In this case the steam turbine system was analysed in the cycle with the two-pressure boiler, see Fig. 4, for the feed water temperature $\mathrm{t}_{\mathrm{FW}}=120^{\circ} \mathrm{C}$. The results of the combined cycle calculations are given in Table 2 . The power output of the steam turbine with respect to that of the gas turbine changes between $35 \%$ and $49 \%$. The power output of the steam turbine increases mainly due to the increase of the gas turbine exhaust gas temperature, but also depends on the ratio of the mass flow rate of the gas turbine exhaust gas to the turbine power output. The live steam pressure depends on the gas turbine exhaust gas temperature and increasers with the increase of this temperature. The pressure $\mathrm{p}_{\mathrm{I}}$ of the low-pressure stage also increases with the increasing exhaust gas temperature $\left(\mathrm{t}_{4}\right)$, but this increase is not large.

The mass flow rates $m_{d}$ of the heating steam taken from the turbine extraction point for heating the condensate in the deaerator are relatively comparable. The mass flow rate $\mathrm{m}_{\mathrm{IT}}$ of the low-pressure steam which is passed from the boiler to the steam turbine decreases with the increasing temperature of the gas turbine exhaust gas.

The combined cycle applied to a system with the gas turbines makes it possible to increase the system efficiency by $35-49 \%$ with respect to the simple gas turbine cycle.

\section{COMBINED MARINE DIESEL ENGINE/ STEAM TURBINE SYSTEMS}

The calculations of the combined Diesel engine/steam turbine systems took into account two marine low-speed engines: 9RTA96C made by Warstsila [6] and 9K98MC made by MAN Diesel \& Turbo [5] which revealed similar power outputs as the gas turbines. The analyses were performed in the combined system with the steam turbine cycle with a single pressure boiler, according to a scheme shown in Fig. 3, and the two-pressure boiler, see Fig. 4. The calculations were performed based on the producer's data for the reference point according to ISO Conditions: ambient air temperature equal to $25^{\circ} \mathrm{C}$ and barometric pressure equal to 1 bar, Table 3 .

Tab. 3. Parameters of marine low-speed Diesel engines used in the combined Diesel engine/steam turbine system [ 5, 6]

\begin{tabular}{|c|c|c|c|c|c|}
\hline \multirow{2}{*}{$\begin{array}{c}\text { Type } \\
\text { of engine }\end{array}$} & $\mathbf{N}_{\mathbf{D}}$ & $\mathbf{m}_{\mathbf{D}}$ & $\mathbf{t}_{\mathbf{4}}$ & $\eta_{\mathbf{D}}$ & $\mathbf{b e}_{\mathbf{D}}$ \\
\cline { 2 - 6 } & $\mathrm{kW}$ & $\mathrm{kg} / \mathrm{s}$ & ${ }^{\circ} \mathrm{C}$ & - & $\mathrm{g} / \mathrm{kWh}$ \\
\hline 9K98MC & 48762 & 134.25 & 232.8 & 0.482 & 174.9 \\
\hline 9RTA96C & 46332 & 104.50 & 271.0 & 0.506 & 166.8 \\
\hline
\end{tabular}

In that case the steam turbine system was analysed for the feed water temperature equal to $t_{\mathrm{FW}}=120^{\circ} \mathrm{C}$. The results of the combined cycle calculations are given in Table 4. Like for the combined system with gas turbines, the caloric value of the fuel was assumed equal to $\mathrm{Wu}=42700 \mathrm{~kJ} / \mathrm{kg}$.

The power of the steam turbine in the combined system ranges from $5.3 \%$ to $6.8 \%$ of the piston engine power. The steam turbine power is larger for the steam turbine cycle with the two-pressure boiler, but this increase in not significant as compared to the power of the turbine with the single-pressure boiler. The turbine power increases with the increasing temperature of the piston engine exhaust gas. The pressure of the live steam for the two-pressure cycle is about 2.5 times as high as that for the single-pressure cycle and it increases with the increase of the temperature $t_{4}$ of the engine exhaust gas.

Tab. 4. Combined Diesel engine-steam turbine cycle

\begin{tabular}{|c|c|c|c|c|c|}
\hline Type & & \multicolumn{2}{|c|}{ 9K98МC } & \multicolumn{2}{|c|}{ 9RTA96C } \\
\hline $\mathbf{N}_{\mathbf{D}}$ & $\mathbf{k W}$ & \multicolumn{2}{|c|}{48762} & \multicolumn{2}{|c|}{46332} \\
\hline $\mathbf{m}_{\mathrm{D}}$ & $\underset{\mathrm{kg} / \mathrm{s}}{\mathrm{K}}$ & \multicolumn{2}{|c|}{134.25} & \multicolumn{2}{|c|}{104.504} \\
\hline $\mathbf{m}_{\mathrm{f}}$ & $\mathrm{kg} / \mathrm{s}$ & \multicolumn{2}{|c|}{2.369} & \multicolumn{2}{|c|}{2.1467} \\
\hline $\mathbf{t}_{4}$ & ${ }^{\circ} \mathrm{C}$ & \multicolumn{2}{|c|}{232.8} & \multicolumn{2}{|c|}{271} \\
\hline \multicolumn{2}{|c|}{ Steam cycle } & Single-pressure & Two-pressure & Single-pressure & Two-pressure \\
\hline$t_{0}$ & ${ }^{\circ} \mathrm{C}$ & 223 & 223 & 261 & 261 \\
\hline $\mathbf{p}_{0}$ & bar & 2.5 & 6 & 4 & 10 \\
\hline $\mathbf{p}_{\mathrm{I}}$ & bar & & 2 & & 2 \\
\hline $\mathbf{t}_{\mathrm{FW}}$ & ${ }^{\circ} \mathrm{C}$ & 120 & 120 & 120 & 120 \\
\hline pu & bar & 2.09 & 2.09 & 2.09 & 2.09 \\
\hline mo & $\mathrm{kg} / \mathrm{s}$ & 5.37 & 3.89 & 5.225 & 3.979 \\
\hline $\mathbf{m}_{\mathrm{d}}$ & $\mathrm{kg} / \mathrm{s}$ & 0.714 & 0.940 & 0.700 & 0.941 \\
\hline $\mathbf{m}_{\mathrm{IT}}$ & $\mathrm{kg} / \mathrm{s}$ & & 2.28 & & 2.91 \\
\hline $\mathbf{N}_{\mathrm{ST}}$ & $\mathbf{k W}$ & 2566 & 2717 & 2906 & 3147 \\
\hline $\mathbf{N}_{\mathrm{ST}} / \mathbf{N}_{\mathrm{D}}$ & - & 0.0526 & 0.0557 & 0.0627 & 0.0679 \\
\hline$\eta_{\text {combi }}$ & - & 0.5074 & 0.5089 & 0.5372 & 0.5398 \\
\hline be $_{\text {combi }}$ & $\mathrm{g} / \mathrm{kWh}$ & 166.2 & 165.7 & 157.0 & 156.2 \\
\hline $\mathbf{m}_{\mathbf{o}} / \mathbf{N}_{\mathrm{D}}$ & $\mathbf{k g} / \mathbf{k W h}$ & 0.3965 & 0.2872 & 0.4060 & 0.3092 \\
\hline $\mathbf{m}_{\mathrm{d}} / \mathbf{m}_{\mathbf{0}}$ & $\%$ & 13.30 & 24.16 & 13.40 & 23.65 \\
\hline $\mathrm{m}_{\mathrm{IT}} / \mathrm{m}_{\mathbf{0}}$ & \% & & 58.61 & & 73.13 \\
\hline $\mathbf{m}_{\mathrm{D}} / \mathbf{N}_{\mathrm{D}}$ & kg/kWh & & & & \\
\hline
\end{tabular}


The live steam mass flow rate for the single-pressure system is larger than that for the two-pressure system. When related to the engine power, this parameter differs insignificantly for the two examined engines. The extraction steam mass flow rate $m_{d}$, as related to that of the live steam, is almost twice as small in the single-pressure system as in the two-pressure system. In the two-pressure system the mass flow rate $\mathrm{m}_{\mathrm{IT}}$ of the low-pressure steam which feeds the steam turbine is equal to $59 \div 73 \%$ of the live steam mass flow rate and increases with the increase of the piston engine exhaust gas temperature.

In the combined system the cycle efficiency increases by $5.6 \div 6.7 \%$ with respect to the power plant with only a Diesel engine.

\section{COMPARISON OF COMBINED GAS TURBINE/STEAM TURBINE AND MARINE LOW-SPEED DIESEL ENGINE/STEAM TURBINE SYSTEMS}

The use of combined systems with the gas turbine or the Diesel engine cooperating with the steam turbine cycle increases the power of the system, and simultaneously increases the power plant efficiency.

In the systems with gas turbines the efficiency increase with respect to the simple gas turbine cycle $(35 \div 49 \%)$ is much larger than that observed in the combined cycle with the Diesel engine, the increase of an order of $5.5 \div 6.7 \%$ with respect to the Diesel engine power, see Table 5.

Tab. 5. Comparing combined cycles

\begin{tabular}{|c|c|c|c|c|c|}
\hline type & $\mathbf{t}_{\mathbf{4}}$ & $\Delta \boldsymbol{\eta} / \boldsymbol{\eta}_{\mathbf{C}}$ & $\Delta \mathbf{b e}^{\prime} \mathbf{b e}_{\mathbf{C}}$ & $\mathbf{N}_{\text {combi } / \mathbf{N}_{\mathbf{C}}}$ & $\mathbf{t}_{\text {exh }}$ \\
\hline & ${ }^{\circ} \mathbf{C}$ & $\%$ & $\%$ & $\%$ & ${ }^{\circ} \mathbf{C}$ \\
\hline \multicolumn{5}{|c|}{ Combined gas turbine/steam turbine system } \\
\hline CYCLON & 570 & 49.03 & -32.91 & 149.0 & 139 \\
\hline GTX100 & 546 & 40.76 & -28.96 & 140.8 & 139 \\
\hline GT10B & 538 & 45.56 & -31.31 & 145.6 & 135 \\
\hline LM2500 & 528 & 40.28 & -28.73 & 140.3 & 135 \\
\hline GT35 & 378 & 34.72 & -25.79 & 134.7 & 131 \\
\hline \multicolumn{7}{|c|}{ Combined Diesel engine/steam turbine system } \\
\hline 9K98MC & 232.8 & \multicolumn{5}{|c|}{5.58} & -5.28 & 105.6 & 131 \\
\hline 9RTA96C & 271 & 6.68 & -6.36 & 106.8 & 131 \\
\hline
\end{tabular}

The two combined systems reveal comparable overall efficiencies, and the resultant specific fuel consumption is also similar. It is noteworthy, however, that the heavy fuel burned in the marine low-speed engines is cheaper than the marine Diesel oil burned in gas turbines. This, in combination with comparable fuel consumption rates, results in lower fuel costs of the combined system with the Diesel engine.

Table 6 gives the energy balance of the combined system with the gas turbines or the marine low-speed Diesel engine.

In the energy balance of the combined system, the power of the main engine is equal to $35 \%$, on average, for the gas turbine and $49 \%$ for the Diesel engine in relation to the energy delivered in the fuel to the engine, while the steam turbine power is equal to $15 \%$ for the system with the gas turbine and $3 \%$ for the system with the Diesel engine. The stack loss and the condenser loss amount to $15 \%$ and $33 \%$ respectively in the system with the gas turbine, and to $15 \%$ and $11 \%$ in the systems with the Diesel engine. The comparable levels of the stack losses for these two systems result from their comparable exhaust gas temperatures.

Other losses in the system with the Diesel engine amount to about $21 \%$, as compared to $3 \%$ in the systems with gas turbines. In the Diesel engine the other losses include the heat taken over in the scavenge air coolers - about $15 \%$, in the lubricating oil cooler - about $3 \%$, and in the jacket water cooler $4 \%$.

Tab. 6. Energy balance of the combined cycle

\begin{tabular}{|c|c|c|c|c|c|c|}
\hline 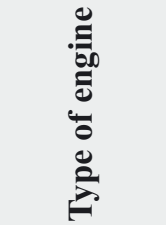 & 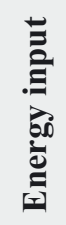 & 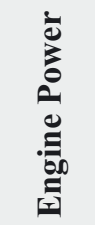 & 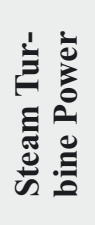 & 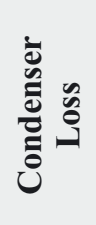 & 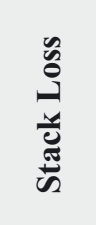 & 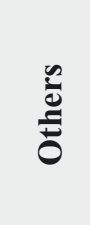 \\
\hline & $\%$ & $\%$ & $\%$ & $\%$ & $\%$ & $\%$ \\
\hline CYCLON & 100 & 34.00 & 16.67 & 32.04 & 13.25 & 4.04 \\
\hline GTX100 & 100 & 37.00 & 15.08 & 30.90 & 13.30 & 3.72 \\
\hline GT10B & 100 & 34.70 & 15.81 & 33.59 & 13.99 & 1.91 \\
\hline LM2500 & 100 & 36.52 & 14.71 & 31.96 & 13.63 & 3.18 \\
\hline GT35 & 100 & 32.00 & 11.11 & 33.94 & 20.28 & 2.66 \\
\hline & \multicolumn{6}{|c|}{ Single-Pressure Combined-Cycle Plant } \\
\hline 9K98МС & 100 & 48.20 & 2.54 & 10.77 & 16.50 & 21.99 \\
\hline 9RTA96C & 100 & 50.55 & 3.17 & 11.42 & 15.68 & 19.18 \\
\hline & \multicolumn{6}{|c|}{ Two-Pressure Combined-Cycle Plant } \\
\hline 9K98МC & 100 & 48.20 & 2.69 & 11.38 & 15.65 & 22.07 \\
\hline 9RTA96C & 100 & 50.55 & 3.43 & 13.16 & 13.58 & 19.28 \\
\hline
\end{tabular}

Steam turbine cycles used in the combined system composed of gas turbines should include a two-pressure boiler, the least, to allow good utilisation of the energy of the hightemperature exhaust gas.

In the combined systems comprising a low-speed Diesel engine, a single-pressure boiler can be used in the steam turbine cycle, as it can secure good utilisation of the exhaust gas heat (much lower temperatures of the exhaust gas, compared to those recorded in the gas turbine).

The live steam parameters in the combined system with gas turbines are much higher than those in the system with the Diesel engine.

The power outputs of the steam turbines in the systems with gas turbines are many times higher than those in the systems with the Diesel engine, compare Tables 2 and 4. For comparable powers of the combined system, the power of the steam turbine amounts to $26 \div 33 \%$ of the power of the entire power plant for the systems with the gas turbines, and to $5.3 \div 6.9 \%$ in the systems with the Diesel engine. In those latter systems the power output of the Diesel engine amounts to $94 \%$ of the power plant power, while in the systems with the gas turbines the power of the gas turbine amounts to $67 \div 74 \%$. For the same total powers of the combined system the power of the Diesel engine is larger $1.3 \div 1.4$ times than that of the gas turbine.

The exit temperatures $t_{\mathrm{EXH}}$ of the exhaust gas in the combined system for the cases with the gas turbine or the Diesel engine are comparable, Table 5. 


\section{FINAL CONCLUSIONS}

There is a possibility to use a combined system composed of the Diesel engine or a gas turbine as the leading engine, and the steam turbine cycle which utilises the heat contained in the engine exhaust gas. These systems reach thermodynamic efficiency comparable with the combined systems of gas turbines cooperating with steam turbines.

\section{Power outputs of the combined systems}

Depending on the adopted variant and main engine load, the use of the combined system can increase the power output of the power plant by $35 \div 49 \%$ in the systems with gas turbines, and by $5 \div 7 \%$ in systems with Diesel engines, with respect to a conventional power plant for the same fuel mass flow rate. Additional power output is generated due to recovery of the energy contained in the exhaust gas from the piston internal combustion engine or the gas turbine. This way the combined system reduces the specific fuel consumption by $26 \div 36 \%$ for cycles with gas turbines and by $5 \div 6.4 \%$ for the cycle with a Diesel engine, with respect to the conventional power plant.

\section{Efficiencies of the combined systems}

The use of the combined system for ship propulsion increases the system efficiency, which leads to the reduction of the specific fuel consumption and, additionally, increases the power of the of propulsion system, without additional fuel consumption. Like the power output, the efficiency of the combined system increases with respect to the conventional power plant, reaching the level of about $43 \div 54 \%$ for maximal power outputs. The efficiency levels for the combined gas turbine/steam turbine and Diesel engine/steam turbine systems are comparable.

\section{Overall power plant dimensions}

The power plant with the combined system with gas turbines is smaller both in mass and dimensions than that with the Diesel engine.

\section{Economic aspects}

The technical and economic analysis of power plant operation should be performed to justify the use of such a power plant. The analysis should take into account both investment and operating costs. At comparable fuel consumption in both combined systems, the cost of burning the heavy fuel oil in the marine power plant with the Diesel engine is lower, as the combined systems with gas turbines burn more expensive marine Diesel oils. But in case of sailing in zones with limits imposed on heavy fuel burning, the use of a combined power plant with gas turbines can be more economically justified.

Depending on the adopted solution, the use of the combined power plant makes it possible to reach the assumed power of the propulsion system at smaller load of the main internal combustion engine, and to reduce the fuel consumption.

\section{NOMENCLATURE}

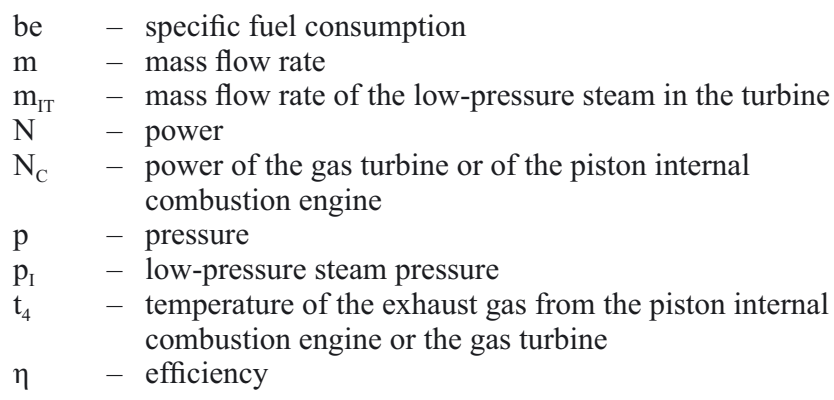

\section{SUBSCRIPTS}

combi - combined system

D - deaerator

D $\quad-$ piston internal combustion engine

exh $\quad-$ outlet duct

$\mathrm{F} \quad-$ fuel

FW - feed water

GT - gas turbine

$\mathrm{K}$ - parameters in the condenser

o $\quad-$ live steam, calculation point

ST - steam turbine

\section{BIBLIOGRAPHY}

1. Advances in Gas Turbine Technology. Chapter (Dzida M.) Possible Efficiency Increasing of Ship Propulsion and Marine Power Plant with the System Combined of Marine Diesel Engine, Gas Turbine and Steam Turbine. ISBN 978-953-307611-9. Book edited by: Dr. Ernesto Benini. INTECH, 2011

2. Dzida, M.: On the possible increasing of efficiency of ship power plant with the system combined of marine diesel engine, gas turbine and steam turbine at the main engine - steam turbine mode of cooperation. Polish Maritime Research, Vol. 16, No.1(59), (2009), pp. 47-52, ISSN 1233-2585

3. Kehlhofer, R.: Combined-Cycle Gas \& Steam Turbine Power Plants, The Fairmont Press, INC., ISBN 0-88173-076-9, USA, 1991

4. MAN B\&M. The MC Engine. Exhaust Gas Date. Waste Heat Recovery System. Total Economy, MAN B\&W Publication S.A., Danish, 1985

5. MAN Diesel \& Turbo \& Turbo. Stationary Engine. Programme $4^{\text {th }}$ edition, Branch of MAN Diesel \& Turbo \& Turbo SE, Germany, Available from www.mandieselturbo.com, 2010

6. Sulzer RTA 96C, Engine Selection and Project Manual, June 2001, Wartsila.

7. ABB ALSTOM POWER Ltd. Gas Turbine and Combined-Cycle Power Plants, Switzerland, CH-50 5401, Baden.

\section{CONTACT WITH THE AUTHORS}

Marek Dzida, Assoc. Prof. Wojciech Olszewski, M. Sc.

Faculty of Ocean Engineering and Ship Technology

Gdansk University of Technology Narutowicza 11/12

80-233 Gdansk, POLAND

e-mail: dzida@pg.gda.pl 